\title{
ASSESSMENT OF THE REGIONAL FREQUENCY ANALYSIS TO THE ESTIMATION OF EXTREME STORM SURGES
}

\author{
Jérôme Weiss ${ }^{(1,2)}$, Pietro Bernardara ${ }^{(1,2)}$ and Michel Benoit ${ }^{(1,2)}$
}

Regional frequency analysis (RFA) is performed to estimate extreme storm surges along the French coasts of the Atlantic Ocean, the English Channel and the Southern part of the North Sea. An insight on the formation of physically homogeneous regions from a criterion of propagation of storms is provided. The treatment of the pairwise dependence structure within a given region through a spatial extreme value copula is also considered, leading to a model coupling physically-based RFA and spatial dependence to describe the probabilistic behavior of extreme storm surges.

Keywords: regional frequency analysis, extreme storm surges, storm propagation, spatial dependence, extreme value copula

\section{INTRODUCTION}

The design of effective coastal protections requires an accurate knowledge of marine flooding hazard: in particular, the occurrence and the statistical distribution of extreme sea levels have to be precisely described. As the random variations of the sea level are contained in the storm surge process, (driven by meteorological conditions and local bathymetry), this problem can come down to conduct statistical analyses of extreme storm surges.

Traditional local statistical analyses of extreme events consist in fitting first an extreme-value distribution from a sample of extreme observations from a given site, and then to infer return levels through extrapolations, (Coles 2001). However, most of at-site time series are generally observed over a span of 20-50 years. When estimations of the thousand-year return level or more are required, as frequent in coastal engineering, local analyses can fail to provide accurate results in this case.

A possible solution to overcome this issue is regional frequency analysis (RFA). If sites are grouped together to form a homogeneous region, uncertainties inherent to local analyses can be reduced through the use of the regional information. RFA states that within a homogeneous region, extreme events are coming from the same regional distribution up to a site-dependent scale factor, often taken as the mean event, deemed to represent the local specificities of the site. For example, in the context of storm surges, this index can incorporate the local effects of bathymetry or shoreline orientation. This method stems from the index flood model of (Darlymple 1960) and have been widely used in hydrology and meteorology to improve the estimation of flood hazard. Applications for coastal hazards are less frequent: (Goda et al. 2010; Van Gelder et al. 2000) conducted a RFA to the estimation of extreme waves, while (Bardet et al. 2011; Bernardara et al. 2011) dealt with extreme storm surges.

(Stedinger and Lu 1995) showed RFA can provide more reliable estimations of extreme quantiles than local analyses. However, (Katz et al. 2002) pointed out some limitations of the RFA when a nonformal version of this method is used: e.g. distortions induced by the normalization by an empirical surge index rather than a theoretical one, the possible spatial heterogeneity of the region (raising the issue of the formation of homogeneous regions), or the spatial dependence of sites not taken into account.

The formation of homogeneous regions remains an open question. Ideally, the region should be both statistically and physically homogeneous. The former point can be checked with statistical tests; see e.g. the procedure described in (Hosking and Wallis 1997). (Bernardara et al. 2011) relied on this test to show that 18 sites located on the French Atlantic coasts could be seen as a statistically homogeneous region. Regarding the physical homogeneity, this requires the knowledge of the phenomena generating extreme storm surges. If a given area is subject to a specific kind of storm, this would mean extreme storm surges are not caused by the same physical phenomena everywhere, advocating for a subdivision of the region. Indeed, if some area-specific atmospheric mechanisms

${ }^{1}$ EDF R\&D, Laboratoire National d'Hydraulique et Environnement (LNHE), 6 quai Watier, BP 49, 78401 Chatou cedex, France

${ }^{2}$ Université Paris Est, Saint-Venant Laboratory for Hydraulics, 6 quai Watier, BP 49, 78401 Chatou cedex, France 
initiating the storms are identified, one can expect to get regional differences in terms of extent and intensity of the storms. In this paper, we propose to form physically homogeneous regions by finding groups of sites whose observed extreme surges are likely to be caused by the same storm events.

Few attempts have been made to assess and model the effects of the spatial dependence between sites in the framework of RFA. (Hosking and Wallis 1997) showed that ignoring the inter-site dependence would induce minimal bias on the estimated quantiles but would certainly underestimate their variance. (Castellarin et al. 2008) evaluated the impact of inter-site correlation on testing the statistical regional homogeneity, while (Bayazit and Önöz 2004; Kjeldsen and Rosbjerg 2002) addressed the effects of inter-site correlation on the variance of regional and local quantiles. (Buishand 1984; Dales and Reed 1989) built a function to characterize the degree of spatial dependence and deduce an equivalent number of independent sites. (Renard 2011; Renard and Lang 2007) explicitly modeled the inter-site dependence with elliptical copulas, where the correlation between two sites directly depends on their distance.

Copulas are indeed useful tools to describe the dependence structure between the components of a random vector, independently of their marginal distributions (Salvadori et al. 2007). When these components are themselves extremes, the corresponding natural copulas are extreme value copulas (Salvadori and De Michele 2011). Therefore, although elliptical copulas (e.g. Gaussian and Student copulas) represent a practical way to describe pairwise dependences through a correlation matrix, they do not belong to the class of extreme value copulas and their use may imply an underestimation of the simultaneous occurrence of extreme events of high magnitude. Moreover, to model different ranges of spatial dependence and to generalize traditional geostatistics, (Bardossy 2006) proposed the use of a spatial copula where the dependence structure between two sites is, roughly speaking, function of their distance. In this paper, this approach is applied to the extreme storm surges. Besides, the propagation of storms generating extreme storm surges could differ from one region to another, depending on e.g. the coastal configuration or the surge-associated wind directions in the region. Such features would lead to the observation of regional patterns in the pairwise dependence structure of extreme storm surges, possibly modeled with a spatial extreme value copula. Return periods of storms generating specific extreme storm surges for a given pair of site could then be easily deduced.

The aim of this proceeding is to propose a model of regionalization of both marginal distributions of extreme storm surges through RFA and spatial dependence structure with a spatial copula. Firstly, the RFA methodology is introduced for the estimation of extreme storm surges. Secondly, a criterion of propagation of storms is derived to form both physically and statistically homogeneous regions. Thirdly, a spatial copula is presented to model the pairwise dependence. Then the results from the application for sites located along the French coasts of the Atlantic Ocean, the English Channel and the Southern part of the North Sea are provided.

\section{METHODS}

\section{Regional frequency analysis (RFA)}

The regional homogeneity assumption is the main hypothesis of RFA. A homogeneous region is a group of sites whose extreme storm surges are coming from the same regional distribution up to a sitedependent scale factor, the surge index. (Sveinsson et al. 2001) developed the "population index flood" model, an analytical RFA where the homogeneity assumption is embedded in the parameters of the theoretical probability distribution, whose mean is the surge index.

For a given homogeneous region of $N$ sites, for a given site $i$ of this region, let $X_{i}$ the initial time series of storm surges, $Y_{i}=X_{i}-u_{i} \mid X_{i}>u_{i}$ the exceedances of a certain high threshold $u_{i}$, sampled from the Peak Over Threshold (POT) method, and $\mu_{i}=E\left(Y_{i}\right)$ the corresponding theoretical surge index. The local POT samples of extreme storm surges $Y_{i}$ are modeled with a two-parameter Generalized Pareto Distribution $\operatorname{GPD}\left(\alpha_{i}, k_{i}\right)$, where $\alpha_{i}>0$ and $k_{i}$ are respectively a scale and a shape parameter. The probability $F_{i}(x)=P\left(X_{i} \leq x\right)$ for $x>u_{i}$ is then given by:

$$
F_{i}(x)=1-\lambda_{i}\left(1+\frac{k_{i}\left(x-u_{i}\right)}{\alpha_{i}}\right)^{-1 / k_{i}}, k_{i} \neq 0
$$

where $\lambda_{i}=P\left(X_{i}>u_{i}\right)$. The regional homogeneity assumption can now be written as:

$$
\mu_{i}=E\left(Y_{i}\right)=\frac{\alpha_{i}}{1-k_{i}} \rightarrow \frac{Y_{i}}{\mu_{i}}=Y_{R} \sim \mathrm{GPD}\left(1-k_{i}, k_{i}\right) \rightarrow k_{i}=k, \forall i=1, \ldots, N
$$


Thus, this regional model implies that the shape parameter is constant throughout the region, and local specificities are incorporated in the scale parameter $\alpha_{i}$. A region is then parameterized by $\left(\alpha_{1}, \ldots, \alpha_{N}, k\right)$. Estimation of these $(N+1)$ parameters can be achieved through e.g. maximum likelihood estimation or the method of L-moments.

\section{Physically-based formation of homogeneous regions}

The formation of homogeneous regions should be made upon physical criteria, in relation to the understanding of mechanisms governing the generation of extreme storm surge events. These ones are mainly observed during storms, through the combination of high winds and low atmospheric pressures.

This paper proposes to form regions whose extreme surges are likely to be caused by the same storm events. A region should thus reflect the most likely spatial extent of a storm affecting the area. For this purpose, a criterion of spatial propagation of extreme storm surges occurred during a storm is defined, namely the probability $p_{i j}$ that both sites $i$ and $j$ are impacted by a storm given that at least one of these sites is hit by this storm:

$$
p_{i j}=P\left(X_{i}>u_{i} \cap X_{j}>u_{j} \mid X_{i}>u_{i} \cup X_{j}>u_{j}\right)
$$

Then, a hierarchical cluster analysis by the Ward's method is performed on the distances between sites induced by the quantities depicted in (3) to highlight different regions. By construction, when a storm hits a given site, its corresponding region is made of the remaining sites which are the most likely impacted by the storm.

Note that here a storm is said to impact a site if and only if an extreme surge was observed at this site during the storm. Moreover, (3) is related to the simultaneous occurrence of extreme surges at different sites. This concept of simultaneity needs to be defined with care: in particular, the time taken by the storm to propagate between two sites must be taken into account, as well as the time taken by the tide to propagate if the variable of interest is the skew storm surge (i.e. the storm surge occurring around the time of high tide).

This procedure can be performed without any other information than the storm surge observations and their time of occurrence. The way to construct physically homogenous regions is likely to change according to the variable of interest; however, the method proposed here could potentially be applied to other environmental variables in the framework of RFA.

Once physically homogeneous regions are obtained, (Hosking and Wallis 1997) proposed a procedure to test its statistical homogeneity: firstly, a discordancy measure is derived to identify sites that are grossly discordant with the region; secondly the regional homogeneity is assessed with a heterogeneity measure which compares the observed dispersion between sites to the expected dispersion in a homogeneous region.

\section{Modeling the bivariate spatial dependence}

The copula theory provides a unifying framework to model the dependence structure of random variables. Indeed, from (Sklar 1959), the joint probability distribution of random variables can be independently separated into marginal distributions and a function containing the dependence structure, the copula. For a thorough description of copulas and their possible applications in environmental sciences, see e.g. (Salvadori et al. 2007). Following the multivariate extreme value theory for joint excesses over a threshold, see e.g. (Beirlant et al. 2004), the bivariate probability distribution between extreme storm surges observed at two different sites $i$ and $j$ from a given homogeneous region can be approximated by the following expression:

$$
P\left(X_{i} \leq x_{i}, X_{j} \leq x_{j}\right) \approx C_{i j}\left(F_{i}\left(x_{i}\right), F_{j}\left(x_{j}\right)\right), x_{i}>u_{i}, x_{j}>u_{j}
$$

where $F_{i}$ and $F_{j}$ are the marginal GPDs given by (1), and $C_{i j}$ an extreme value copula, i.e. a max-stable copula (Salvadori and De Michele 2011). Note that this model is only valid for simultaneous occurrences of extreme storm surges, namely $x_{i}>u_{i}$ and $x_{j}>u_{j}$. The Gumbel copula is used here:

$$
C_{i j}(u, v)=\exp \left\{-\left[(-\log (u))^{\theta_{i j}}+(-\log (v))^{\theta_{i j}}\right]^{\frac{1}{\theta_{i j}}}\right\}, u, v \in[0,1]
$$


where $\theta_{i j} \geq 1$ is the parameter controlling the strength of dependence between the two variables: independence and perfect dependence are respectively obtained when $\theta_{i j}=1$ and $\theta_{i j} \rightarrow+\infty$.

The model proposed here is set in a spatial context, and the dependence structure between two sites is assumed to depend only on their distance, not on their locations. Inspiring from (Bardossy 2006), a spatial copula is thus derived:

$$
d\left(X_{i}, X_{j}\right)=h \Rightarrow C_{i j}=C_{h} \Rightarrow \theta_{i j}=\theta_{h}
$$

In order to reflect that pairwise dependence decays with distance, a kind of correlation function $\rho$ is used in the expression of $\theta_{h}$ :

$$
\theta_{h}=\frac{1}{1-\rho(h)}
$$

Note that this parameterization ensures that given two sites distant of $\mathrm{h}$, independence and perfect dependence are respectively obtained when $h \rightarrow+\infty$ and $h \rightarrow 0$. Moreover, the two-parameter Matern function is employed here because of its flexibility to catch essential spatial features:

$$
\rho(h)=\rho(h, \phi, \kappa)=\frac{1}{2^{\kappa-1} \Gamma(\kappa)}\left(\frac{h}{\phi}\right)^{\kappa} K_{\kappa}\left(\frac{h}{\phi}\right)
$$

where $\phi$ and $\kappa$ are respectively a shape and a scale parameter, $\Gamma$ the Gamma function and $K_{\kappa}$ the modified Bessel function of the third kind of order $\kappa$.

Thus, for a given homogeneous region, this model of spatial dependence is only parameterized by $(\phi, \kappa)$, which can be estimated through a maximum-likelihood procedure. In particular, as only the bivariate distributions are available from (4), an approximation of the full likelihood can be obtained with the pairwise likelihood (Davison and Gholamrezaee 2012). Moreover, although the model (4) is only valid for simultaneous observations of extreme storm surges, the censored likelihood approach, introduced by (Ledford and Tawn 1996), also allows taking into account the information carried by the pairs where only one component is over the threshold. The validation of this model can be performed using the procedure described in (Genest et al. 2011) to test the adequation of the Gumbel copula to the data with the Pickands dependence function.

The stationarity hypothesis from (6) makes connection with RFA: as pairs from the same homogeneous region contribute to build the spatial copula, it can be seen as a regionalization of the dependence structure. Moreover, the way proposed to form homogeneous justifies that pairs of sites from the same region share the same spatial copula. As extreme storm surges in a region are likely to be generated by the same storms, the spatial copula reflects the regional intensity of the simultaneous extremes surges occurred during a storm, and may change from one region to another.

\section{DATA}

The raw data used in this study are temporal series of hourly sea level observations collected at 27 ports along the French coasts of the Atlantic Ocean, the English Channel and the Southern part of the North Sea, see Fig. 1. French data are supplied by SHOM (Service Hydrographique et Océanographique de la Marine, France) and available on the REFMAR (Réseaux de référence des observations marégraphiques) website, while UK data are supplied by BODC (British Oceanographic Data Centre, UK). The series are ranging from 1846 (Brest, France) to the end of 2010, show a mean effective duration of 34.6 years and display missing values. 


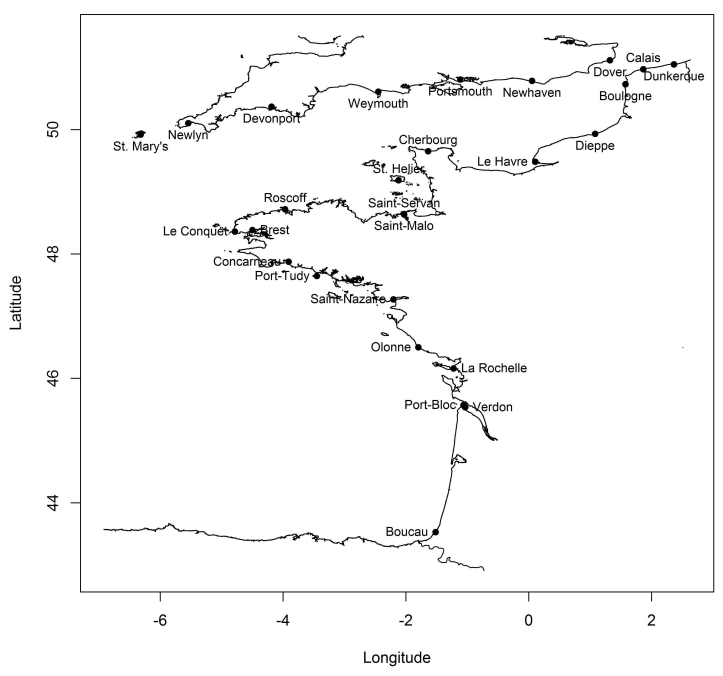

Figure 1. Location of the 27 sites

Care should be taken for the extraction of storm surges. Indeed, local mean sea levels may be affected by eustatism (i.e. the long-term alteration of mean sea levels caused by either geological or climate changes), while tidal predictions are given for the present time. In order to calculate the actual surges of past periods, the sea level must be corrected from a possible eustatism. If annual sea levels, calculated following the PSMSL (Permanent Service for Mean Sea Level) recommendations, show significant linear trends, then raw sea level data are corrected to ensure the stationarity of annual sea levels.

In regions with strong tidal influence, coastal flooding hazard is more marked around the times of high tide. Therefore, we restricted our attention to skew surge series, in order to describe the surge contribution at the maximum tidal level. The skew surge is defined as the (algebraic) difference between the maximum observed sea level around the time of theoretical (predicted) high tide and the predicted high tide level, as illustrated by Fig. 2. Thus, the resulting skew surge series have a temporal resolution of approximately 12.4 hours. For a more detailed introduction on skew surges, see (Bardet et al. 2011; Bernardara et al. 2011; Simon 2007; Weiss et al. 2012).

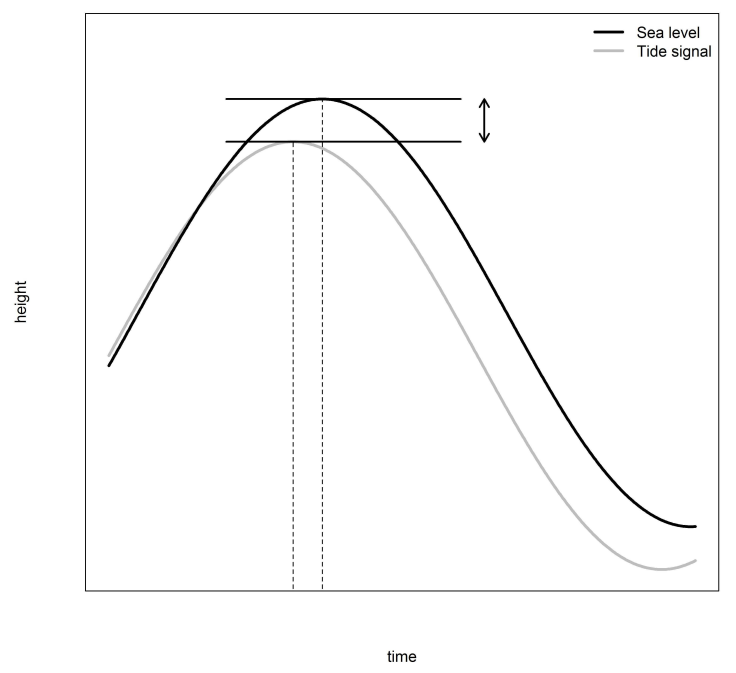

Figure 2. Definition of the skew surge

Here, extreme storm surges are defined in the framework of the POT method. Local thresholds are set to get two peaks a year on average. However, for a given site, threshold exceedances are likely to 
occur in clusters (whose sizes depend on the storm duration) and declustering techniques are applied to get independent local samples of extreme storm surges. To ensure the independence of peaks, a temporal criterion of at least $72 \mathrm{~h}$ between clusters was fixed. These resulting local POT samples are the basis of the RFA.

The next step is the extraction of the spatial storms, i.e. the 27 simultaneous skew storm surges when one extreme is observed in at least one site. In order to take into account both the typical duration of a storm and the propagation time of the tide over the area, extreme skew storm surges occurring at different sites with less than $2 \times 12.4 \mathrm{~h}$ time lag are supposed to be produced by the same storm and are said to be part of the same spatial storm. Therefore, a spatial storm is a purely statistical object which provides information on the spatial extent of the extremes surges generated by a storm: for any of the 27 sites, either an extreme surge (exceeding the threshold) appeared during the storm, or it was not impacted by the storm (no extreme surge), or no data have been recorded during the storm. 883 spatial storms are thus extracted, being both the basis of the formation of homogeneous regions and the estimation of the spatial copulas. As an illustration, the spatial storms corresponding to the Great October Storm of 1987 and the Xynthia storm of February 2010 are represented on Fig. 3.
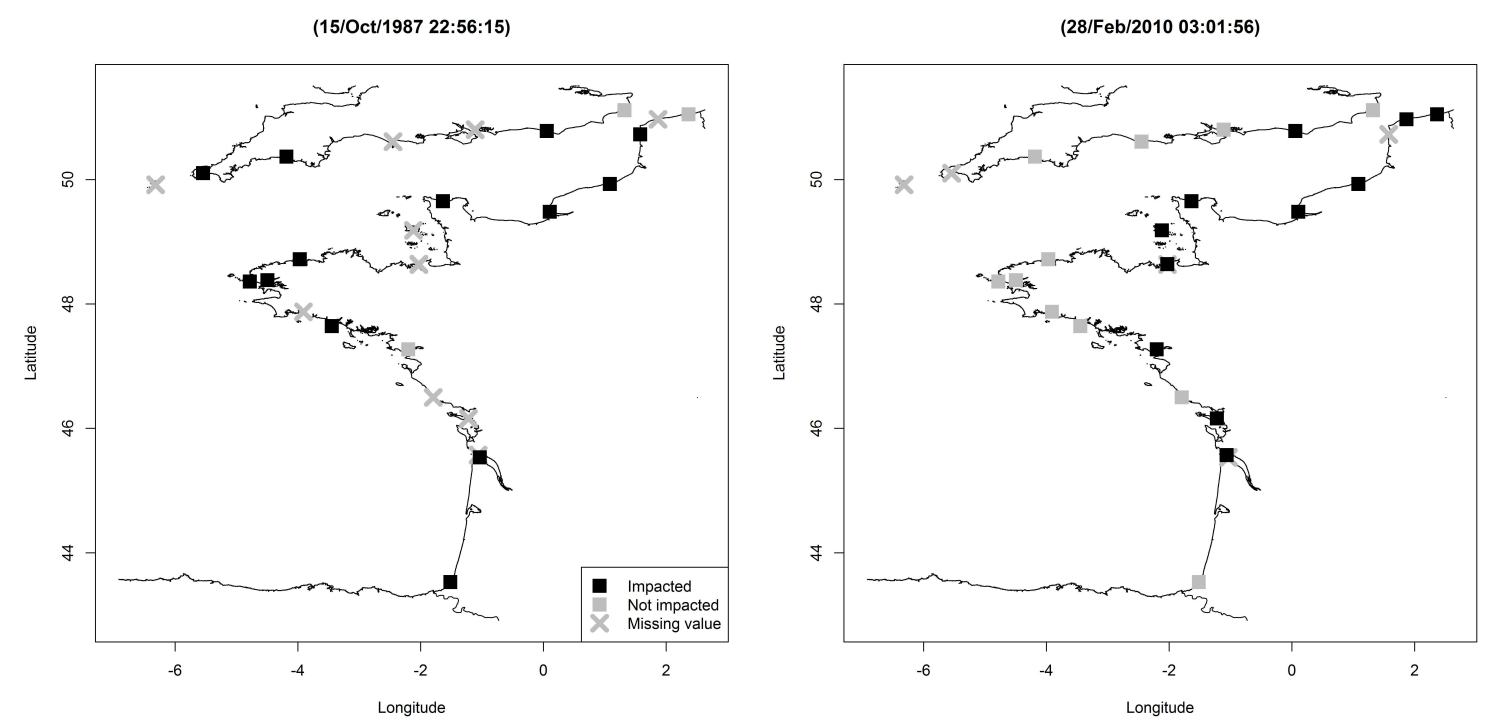

Figure 3. Examples of remarkable storms: the Great October Storm of 1987 (left) and the Xynthia storm of February 2010 (right) - sites impacted (black squares), sites not impacted (grey squares) and sites with missing values during the storm (grey crosses)

\section{RESULTS}

\section{On the formation of homogeneous regions}

A method to build homogeneous regions in a physical sense, based on the propagation of storms, is proposed. From the hierarchical cluster analysis on the distances between sites induced by the pairwise criteria of propagation of storms (3), three geographically coherent regions are obtained: the Atlantic region, the Western English Channel region and the Eastern English Channel region (Fig. 4). Therefore, within a region, extreme surges are likely to be caused by the same physical storm events. The statistical homogeneity of these regions was accepted with the Hosking and Wallis test. 


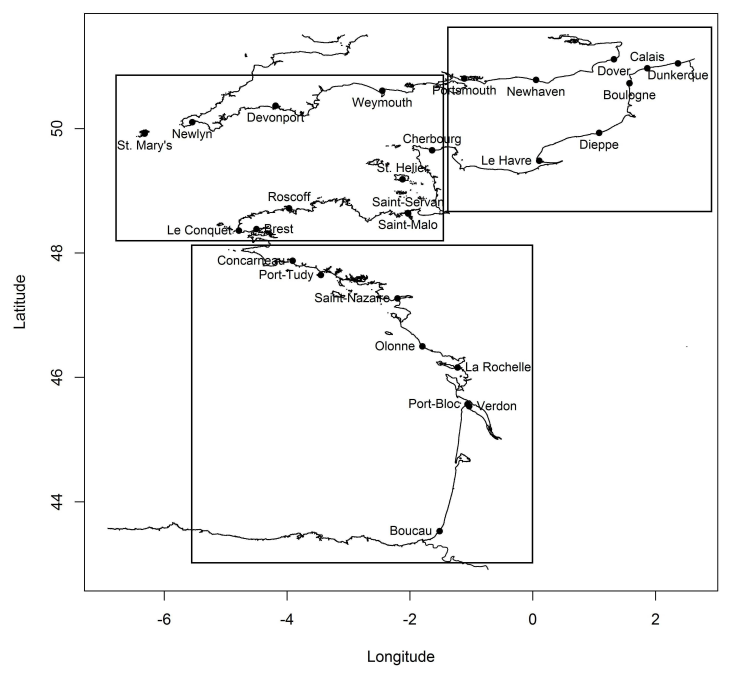

Figure 4. Physically homogeneous regions obtained with the hierarchical cluster analysis from the criterion of propagation of storms

Besides, different patterns of the spatial propagation of extreme surges can be highlighted in each region: in Fig. 5 are plotted the criteria of propagation of storms, equation (3), for pairs located in a given region, in function of the distance between the two sites.

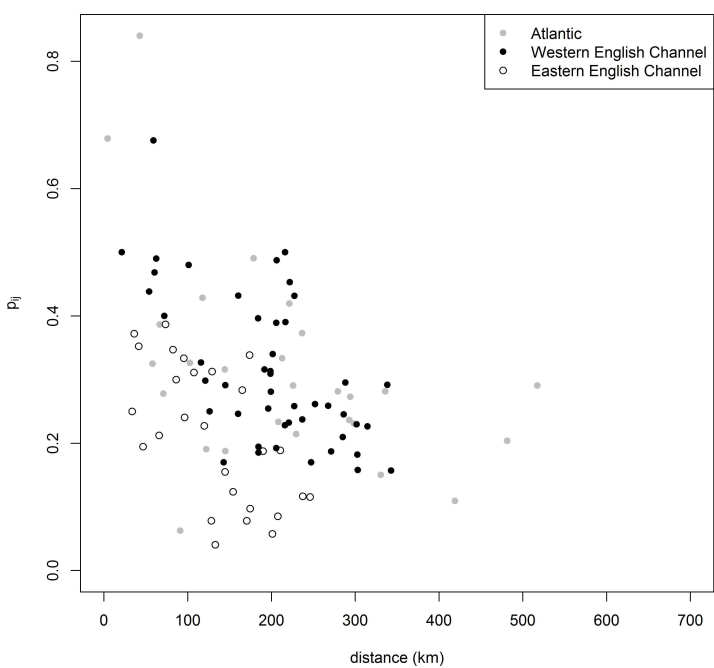

Figure 5. Criteria of propagation of storms for pairs located in a given region, in function of the pairwise distance

Thus, for a given pairwise distance, a storm is more likely to propagate between two sites located in the Western English Channel or in the Atlantic Ocean, than between a pair of sites located in the Eastern English Channel. An explanation for this latter region may be due to the Dover Strait and the different coastal exposures in this area: North Sea storms easily impact the North of the Opal Coast (Dunkerque and Calais), but do not necessarily impact the West of the Opal Coast (Boulogne and Dieppe), even at small distance; conversely, western and south-western flows can produce extreme surges on the West of the Opal Coast, but not necessarily on the North of the Opal Coast. Regarding the Western English Channel, the corridor effect due to the coastal configuration of this region may be a justification: the great majority of the sites are highly sensitive to western and south-western flows, even if the coastal orientations are different. Lastly, the Atlantic region displays a more dispersed pattern in the propagation of storms: this may be caused by a more latitudinally spread configuration. In 
particular, this region is more affected by south-western flows from La Rochelle to Concarneau, whereas western flows at lower latitudes are more likely to cause extreme surges from Bayonne to PortBloc.

\section{On the estimation of marginal distributions through RFA}

From the RFA model in equation (2), each homogeneous region is characterized a common GPD shape parameter and local scale parameters, estimated by maximum likelihood. Resulting GPDs passed the upper-tail Anderson-Darling test for goodness-of-fit. Estimates of the regional shape parameters are given in Table 1 and return level plots in Fig. 6, Fig. 7 and Fig. 8. Note that the visual impression of outliers relates to extreme storm surges occurred during the most powerful spatial storms: the 1953 North Sea flood (Dunkerque), the Great October Storm of 1987 (Port-Tudy, Brest, Le Conquet, Cherbourg, Dieppe), the Lothar and Martin storms of December 1999 (Verdon) and the Xynthia storm of February 2010 (La Rochelle).

\begin{tabular}{|c|c|}
\hline \multicolumn{2}{|c|}{$\begin{array}{c}\text { Table 1. Estimates of the regional shape parameters } \\
\text { (standard deviation in parentheses) }\end{array}$} \\
\hline Region & $\mathrm{k}$ \\
\hline Atlantic & $-0.03(0.04)$ \\
Western English Channel & $-0.05(0.03)$ \\
Eastern English Channel & $0.04(0.04)$ \\
\hline
\end{tabular}

Boucau

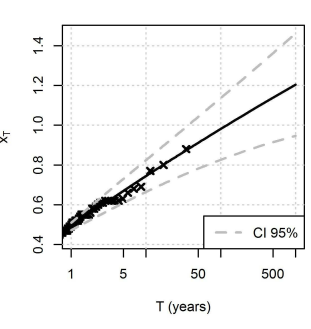

Olonne

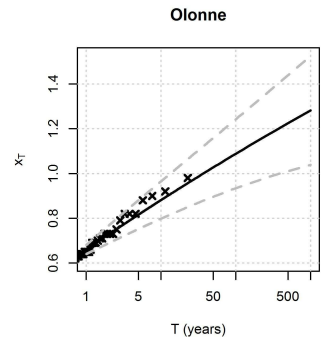

Port-Bloc

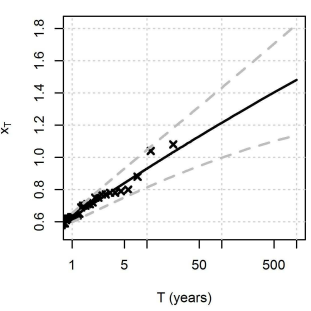

Saint-Nazaire

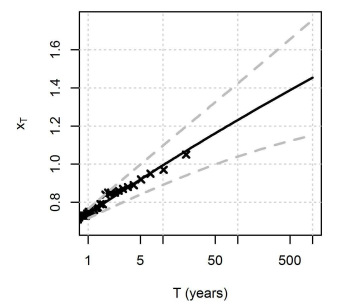

Verdon

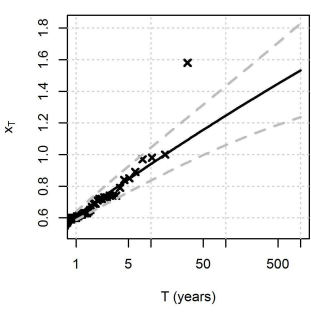

Port-Tudy

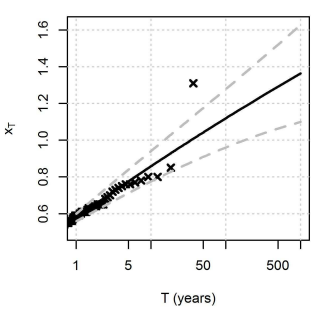

La Rochelle

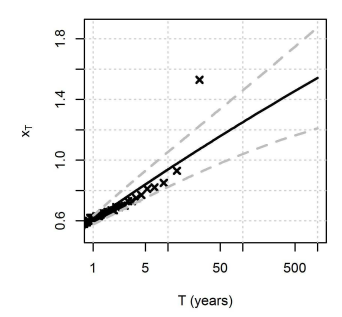

Concarneau

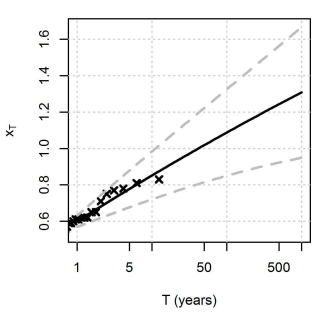

Figure 6. Return level plots of sites from the Atlantic region with $95 \%$ confidence interval 

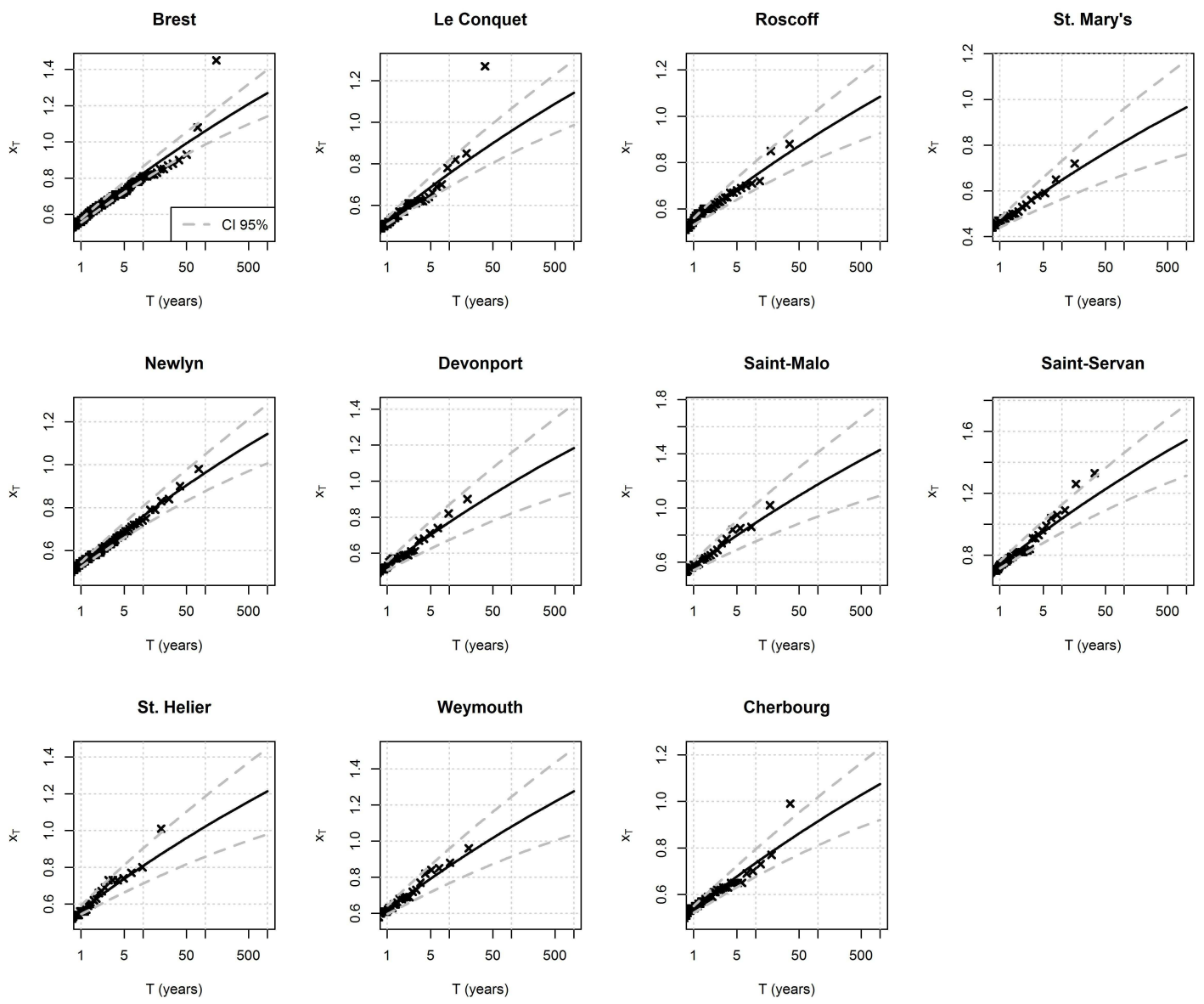

Figure 7. Return level plots of sites from the Western English Channel region with $95 \%$ confidence interval
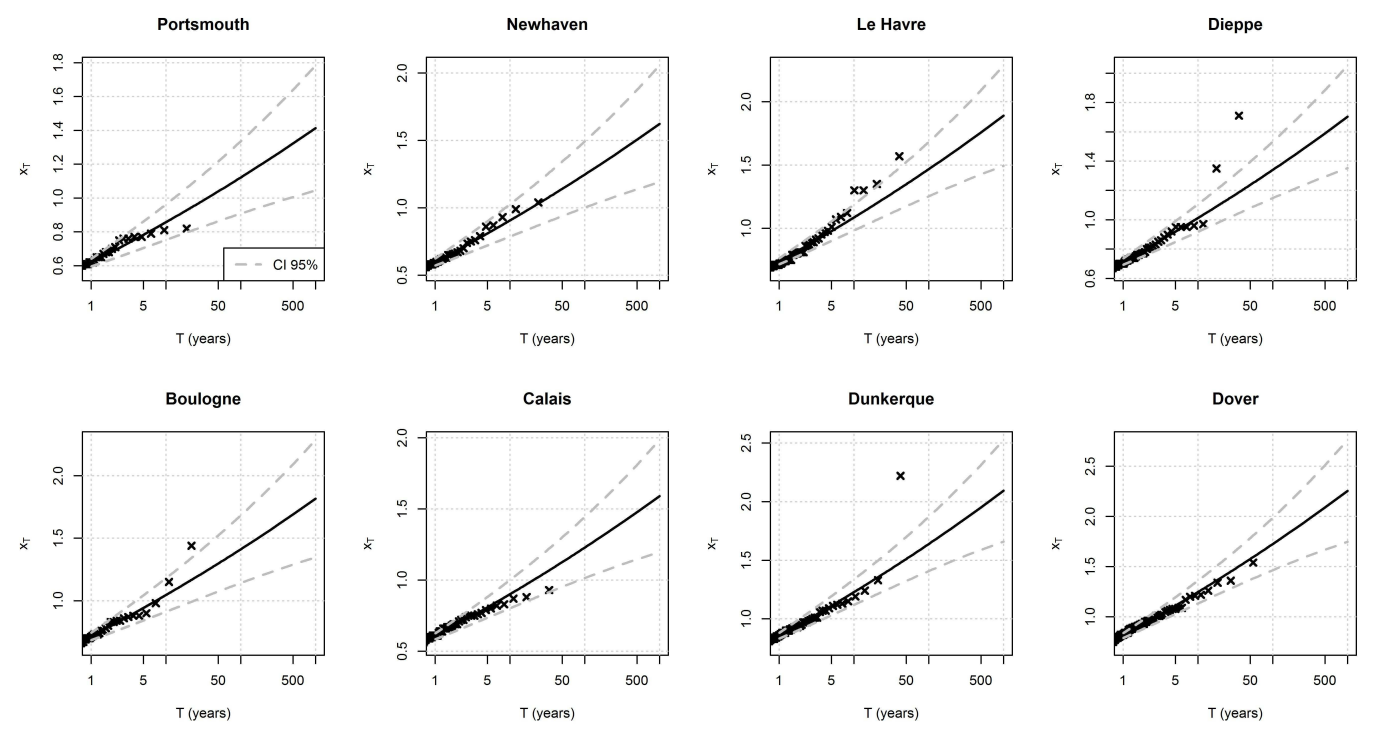

Figure 8. Return level plots of sites from the Eastern English Channel region with $95 \%$ confidence interval 
A higher intensity of extreme surges can be expected in the Eastern English Channel, since the shape parameter is positive in this region. A first explanation could be that North Sea storms are likely to be more powerful than Atlantic storms. Moreover, during south-western flows, the funnel shaped coasts around the Dover Strait can imply a piling-up of oceanic waters and produce significant storm surges (Héquette and Rufin-Soler 2007).

\section{On the estimation of spatial dependence through spatial copulas}

For each region, a spatial copula - equations (5) to (8) - is estimated through the maximization of the pairwise-censored likelihood, in order to describe the regional pattern of pairwise spatial dependence of extreme storm surges. Results are summarized in Fig. 9.

$\theta_{\mathrm{h}}$

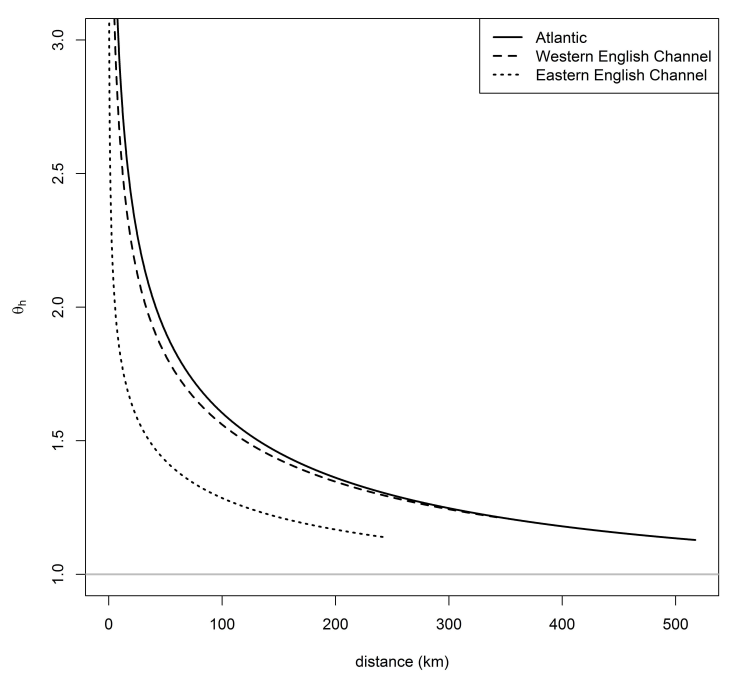

Figure 9. Regional estimates of the spatial copulas: evolution of the Gumbel copula parameter in function of the region and the pairwise distance between sites

This spatial model completes the features observed in Fig. 5: for a given distance between two sites, the intensity of the pairwise dependence is the strongest in the Atlantic Ocean and in the Western English Channel (similar curves), whereas it is the weakest in the Eastern English Channel. Moreover, pairwise independence is never reached, event at long distance: the probability that a storm simultaneously generates very large storm surges at two different sites from the same region is not zero from this model (asymptotic dependence). For each pair of sites, the adequation of the Gumbel copula to the extreme storm surges was successfully tested, thus validating the proposed model.

A possible application of such a model is the calculation of the return period of the storm causing the simultaneous occurrence of the $T$-year skew storm surges for a given pair of sites in a homogeneous region. The model implies that this return period is different according to the considered region: see Fig. 10. For example, if $T=100$ years, for a pair of sites distant of $200 \mathrm{~km}$, this return period is about 300 years in both the Western English Channel and the Atlantic regions, and 530 years in the Eastern English Channel. 


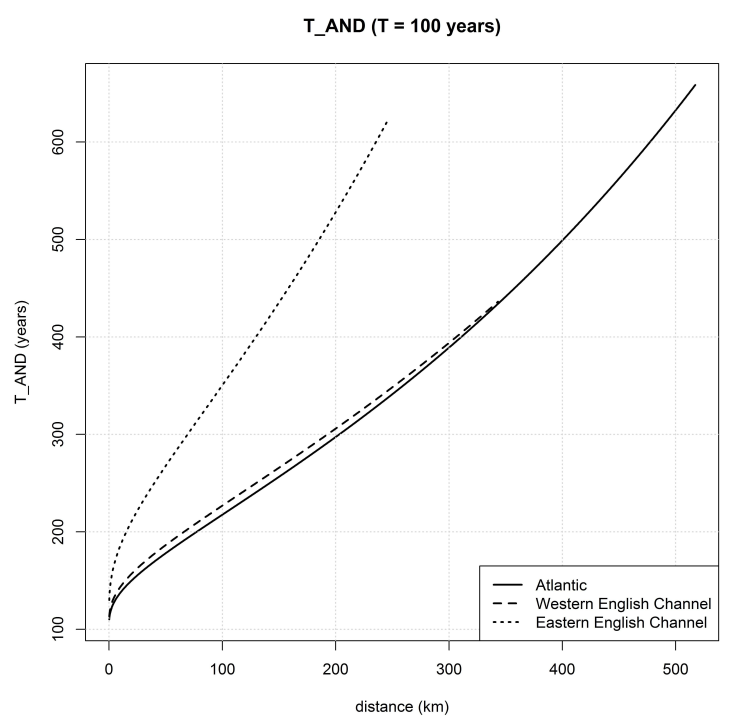

Figure 10. Return period of the storm causing the simultaneous occurrence of the $T$-year skew storm surges for a pair of sites in function of their distance

\section{CONCLUSIONS}

The probabilistic behavior of extreme storm surges along the French coasts of the Atlantic Ocean, the English Channel and the Southern part of the North Sea is modeled through the coupling of RFA and spatial dependence. Indeed, RFA exploits the available regional information to reduce uncertainties inherent to traditional local analyses for the estimation of extreme events. Moreover, a criterion of propagation of storms is proposed to:

- Build physically homogeneous regions (the Atlantic region, the Western and the Eastern English Channel regions) whose extreme storm surges are likely to be generated by the same storm events.

- Highlight specific regional patterns in the propagation of extreme surges occurring during storms. Each region is then characterized by:

- A common regional probability distribution shared by all sites (up to the local surge index) to estimate the probability of occurrence of extreme skew storm surges.

- A specific regional pairwise dependence structure, modeled with a spatial copula, to estimate the simultaneous occurrence of extreme storm surges.

Future work could be the inclusion of both the pairwise distance and the direction of the storm propagation to model the dependence structure, as well as the application of this model to other coastal hazards.

\section{ACKNOWLEDGMENTS}

The permission to publish the results of this ongoing research study was granted by the EDF (Electricité De France). The results in this paper should, of course, be considered as R\&D exercises without any significance or embedded commitments upon the real behavior of the EDF power facilities or its regulatory control and licensing. The authors would like to acknowledge the SHOM (Service Hydrographique et Océanographique de la Marine, France), the REFMAR (Réseaux de référence des observations marégraphiques, France) and the BODC (British Oceanographic Data Centre, UK) for providing the data used in this study.

\section{REFERENCES}

Bardet, L., C.-M. Duluc, V. Rebour and J. L'Her. 2011. Regional frequency analysis of extreme storm surges along the French coast, Natural Hazards and Earth System Sciences, 11, 6, 1627-1639.

Bardossy, A. 2006. Copula-Based Geostatistical Models for Groundwater Quality Parameters, Water Resources Research, 42, 11, W11416. 
Bayazit, M. and B. Önöz. 2004. Sampling variances of regional flood quantiles affected by intersite correlation, Journal of Hydrology, 291 (1-2), 42-51

Beirlant, J., U. Goegebeur, J. Segers and J. L. Teugels. 2004. Statistics of Extremes : Theory and Applications, Wiley.

Bernardara, P., M. Andreewsky and M. Benoit. 2011. Application of the Regional Frequency Analysis to the estimation of extreme storm surges, J. Geophys. Res., 116, C02008, 1-11.

Buishand, T. A. 1984. Bivariate extreme-value data and the station-year method, Journal of Hydrology, 69, 77-95.

Castellarin, A., D. H. Burn and A. Brath. 2008. Homogeneity testing: how homogeneous do heterogeneous cross-correlated regions seem?, Journal of Hydrology, 360, 67-76.

Coles, S. 2001. An introduction to statistical modeling of extreme values, London, Springer-Verlag.

Dales, M. Y. and D. W. Reed. 1989. Regional flood and storm hazard assessment, 102, Institute of Hydrology, Wallingford, Oxon.

Darlymple, T. 1960. Flood Frequency Analysis, 1543-A, US Geological Survey, Water Supply Paper,

Davison, A. C. and M. M. Gholamrezaee. 2012. Geostatistics of extremes, Proceedings of the Royal Society, series A, 468, 581-608.

Genest, C., I. Kojadinovic, J. Nešlehová and J. Yan. 2011. A goodness-of-fit test for bivariate extremevalue copulas, Bernoulli, 17, 253-275.

Goda, Y., M. Kudaka and H. Kawai. 2010. Incorporating of Weibull distribution in L-moments method for Regional Frequency Analysis of Peak Over Threshold wave heights, Proc. 32th Int. Conf. on Coastal Eng. (ICCE 2010), Shangai.

Héquette, A. and C. Rufin-Soler. 2007. Rapport scientifique final : Plages a risque (PAR) / Beaches at risk (BAR), Progamme INTERREG IIIa Phase II, Université du Littoral Côte d'Opale de Dunkerque, Dunkerque.

Hosking, J. R. M. and J. R. Wallis. 1997. Regional Frequency Analysis. An approach based on Lmoments, Cambridge, Cambridge University Press.

Katz, W., M. B. Paralange and P. Naveau. 2002. Statistics of extreme in hydrology, Advances in Water Resources, 25, 1287-1304.

Kjeldsen, T. R. and D. Rosbjerg. 2002. Comparison of regional index flood estimation procedures based on the extreme value type I distribution, Stochastic environmental research and risk assessment, 16, 5, 358-373.

Ledford, A. W. and J. A. Tawn. 1996. Statistics for near independence in multivariate extreme values, Biometrika 83, 169-187.

Renard, B. 2011. A Bayesian Hierarchical Approach To Regional Frequency Analysis, Water Resources Research, 47, W11513.

Renard, B. and G. Lang. 2007. Use of a Gaussian copula for multivariate extreme value analysis :some case studies in hydrology, Advances in Water Resources, 30, 897-912.

Salvadori, G. and C. De Michele. 2011. Estimating strategies for multiparameter multivariate extreme value copulas, Hydrol. Earth Syst. Sci., 15, 141-150.

Salvadori, G., C. De Michele, N. T. Kottegoda and R. Rosso. 2007. Extremes in Nature, An approach using copulas, Dordrecth, Springer.

Simon, B. 2007. La marée océanique côtière, Editions de l'Institut Océanographique.

Sklar, A. 1959. Fonctions de répartition à n dimensions et leurs marges, Publ. Inst. Statist. Univ. Paris, 8, 229-231.

Stedinger, J. R. and L.-H. Lu. 1995. Appraisal of regional and index flood quantile estimators, Stochastic Hydrology and Hydraulics 9, 1, 49-75.

Sveinsson, O. G. B., D. C. Boes and J. D. Salas. 2001. Population index flood method for regional frequency analysis, Water Resources Research, 37, 11, 2733- 2748.

Van Gelder, P. H. A. J. M., J. De Ronde, N. M. Neykov and P. Neytchev. 2000. Regional Frequency Analysis of Extreme Wave Heights: Trading Space for Time, Proc. 27th Int. Conf. on Coastal Eng. (ICCE 2000), Sydney.

Weiss, J., P. Bernardara, M. Andreewsky and M. Benoit. 2012. Seasonal autoregressive modeling of a skew storm surge series, Ocean Modelling, 47, 41-54. 